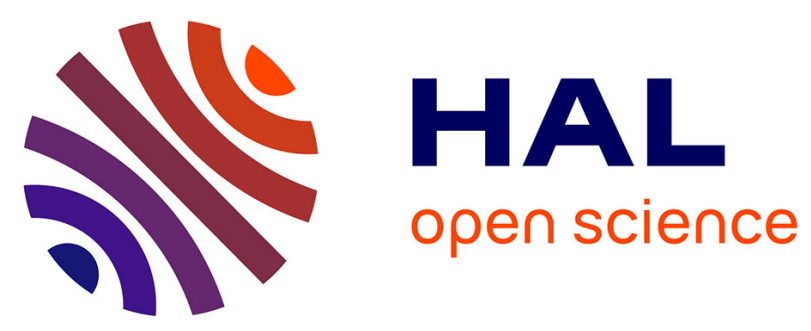

\title{
Constitutional Mosaic Genome-Wide Uniparental Disomy due to Diploidization: an Unusual Cancer-Predisposing Mechanism.
}

Valeria Romanelli, Julian Nevado, Mario Fraga, Alex Martín Trujillo, Maria Ángeles Mori, Luis Fernández, Guiomar Pérez de Nanclares, Víctor Martínez-Glez, Guillermo Pita, Heloisa Meneses, et al.

\section{To cite this version:}

Valeria Romanelli, Julian Nevado, Mario Fraga, Alex Martín Trujillo, Maria Ángeles Mori, et al.. Constitutional Mosaic Genome-Wide Uniparental Disomy due to Diploidization: an Unusual Cancer-Predisposing Mechanism.. Journal of Medical Genetics, 2010, 48 (3), pp.212. 10.1136/jmg.2010.081919 . hal-00586981

\section{HAL Id: hal-00586981 https://hal.science/hal-00586981}

Submitted on 19 Apr 2011

HAL is a multi-disciplinary open access archive for the deposit and dissemination of scientific research documents, whether they are published or not. The documents may come from teaching and research institutions in France or abroad, or from public or private research centers.
L'archive ouverte pluridisciplinaire HAL, est destinée au dépôt et à la diffusion de documents scientifiques de niveau recherche, publiés ou non, émanant des établissements d'enseignement et de recherche français ou étrangers, des laboratoires publics ou privés. 


\section{Constitutional Mosaic Genome-Wide Uniparental Disomy due to Diploidization: an Unusual Cancer-Predisposing Mechanism.}

Valeria Romanelli ${ }^{1,2}$, Julián Nevado ${ }^{1,2}$, Mario Fraga ${ }^{3}$, Alex Martín Trujillo ${ }^{4}$, Maria Ángeles

Mori $^{1,2}$, Luis Fernández ${ }^{1,2}$, Guiomar Pérez de Nanclares ${ }^{5}$, Víctor Martínez-Glez ${ }^{1,2}$, Guillermo

Pita $^{6}$, Heloisa Meneses ${ }^{1,2,7}$, Ricardo Gracia ${ }^{8}$, Sixto García-Miñaur ${ }^{1,2}$, Purificación García de Miguel $^{9}$, Beatriz Lecumberri $^{10}$, José Ignacio Rodríguez ${ }^{11}$, Anna González Neira ${ }^{6}$, David Monk ${ }^{4}$, Pablo Lapunzina ${ }^{1,2,12}$.

(1) INGEMM, Instituto de Genética Médica y Molecular, IDIPAZ-Hospital Universitario La Paz, Universidad Autónoma de Madrid, Madrid, 28046, Spain;

(2) CIBERER, U753-Centro de Investigación Biomédica en Red de Enfermedades Raras, ISCIII.

(3) Centro Nacional de Biotecnología (CNB-CSIC), Universidad Autónoma de Madrid, Madrid, 28049, Spain;

(4) Cancer Epigenetic and Biology Program (PEBC), Institut D’Investigació Biomedica de Bellvitge (IDIBELL), Hospital Duran i Reynals, Barcelona, 08901, Spain.

(5) Laboratorio de Genética Molecular, Unidad de Investigación, Hospital de Txagorritxu, Vitoria, 01006, Spain. CIBERER, U725A- Centro de Investigación Biomédica en Red de Enfermedades Raras, ISCIII.

(6) CNIO. Centro Nacional de Investigaciones Oncológicas, Madrid, 28029, Spain;

(7) Department of Genetics, Universidad Federal de Rio de Janeiro, 21941-901, Brazil;

(8) Servicio de Endocrinología Infantil, IDIPAZ, Hospital Universitario La Paz, Universidad Autónoma de Madrid, Madrid, 28046, Spain;

(9) Servicio de Oncología Pediátrica, Hospital Universitario La Paz, Universidad Autónoma de Madrid, Madrid, 28046, Spain; 
(10) Servicio de Endocrinología, Hospital Universitario La Paz, Universidad Autónoma de Madrid, Madrid, 28046, Spain;

(11) Departamento de Anatomía Patológica, Hospital Universitario La Paz, Universidad Autónoma de Madrid, Madrid, 28046, Spain;

(12) RESSC, Registro Español de Síndromes de Sobrecrecimiento, Madrid, 28046, Spain.

\section{Address for correspondence:}

Pablo Lapunzina M.D, Ph.D

INGEMM- Instituto de Genética Médica y Molecular

IdiPAZ-Hospital Universitario La Paz

Paseo de la Castellana 261

28046- Madrid- Spain

Phone: +34 917277217

Fax: $\quad+34912071040$

plapunzina.hulp@salud.madrid.org

KEY WORDS: Beckwith-Wiedemann syndrome; paternal uniparental disomy; diploidization; imprinting. 


\section{Summary}

Molecular studies in a patient with Beckwith-Wiedemann syndrome phenotype who developed two different tumors revealed an unexpected observation of almost complete loss of heterozygosity of all chromosomes. We demonstrate, by means of numerous molecular methods that the absence of maternal contribution in somatic cells is due to high-degree $(\sim 85 \%)$ genomewide paternal uniparental disomy. Our observations indicate the genome-wide UPD results from diploidization, and have important implications for genetic counseling and tumor surveillance for the growing number of UPD-associated imprinting disorders. 
Beckwith-Wiedemann syndrome (BWS; [MIM 130650]), one of the commonest overgrowth syndromes, is characterized by pre and postnatal overgrowth, hemihyperplasia, macroglossia and an increased frequency of embryonic tumors [1-3]. It is caused, in up to $90 \%$ of patients, by a variety of genetic or epigenetic alterations within two imprinting sub domains located on human chromosome 11p15 [4;5]. The largest molecular subgroup ( 60-70\% of BWS cases) is comprised of patients carrying an epigenetic error at either the H19DMR (imprinting control region, ICR1) or KvDMR (ICR2) [6], the regions of differential DNA methylation that regulate the appropriate allelic expression of the paternal IGF2 and maternal $C D K N 1 C$ genes respectively. Patients may also have paternal uniparental disomy (patUPD11p15) ( 10-15\%), i.e. two paternally derived copies of chromosome $11 \mathrm{p} 15$ and no maternal contribution, that results in over-expression of the potent mitogen $I G F 2$, and absence of the cell cycle regulator $C D K N I C$ [7]. Chromosome rearrangements comprising maternal translocations/inversions or paternal duplications are rare ( 2-3\% of cases) as are CDKN1C mutations ( 5-7\%).

Loss of heterozygosity ( $\mathrm{LOH})$ may be due either to haploinsufficiency (deletion leading to the lack of contribution of one allele) or uniparental disomy (UPD) when both copies of a chromosome pair originate from one parent. $\mathrm{LOH}$ is a common mechanism of tumorigenesis where it indicates the absence of a functional tumor suppressor gene in the lost region. LOH has been described in almost all cancer types [8]. Localized loss of imprinting (LOI) is a common consequence of $\mathrm{LOH}$ due to the lack of balanced parental contribution in specific region with imprinting either by deletion/duplications or UPD. As stated above, LOH/LOI due to patUPD11p15 is relatively common in BWS and this molecular subgroup of individuals displays one of the highest risks of cancer [9].

Diploidization means the recovery of the normal diploid human chromosome number $(2 n=46)$ from an initially haploid cell $(n=23)$ or triploid zygote $(3 n=69)$. Diploidization is a relatively common mechanism in plants and non-mammalian species but it has been unfrequently observed in humans [10-13]. 
We here report on a woman with BWS phenotype and tumors with almost complete LOH in all chromosomes, showing a near-complete contribution of the paternal genome for the diploid status. Postzygotic diploidization due to failure of maternal DNA replication followed by paternal genome endoreduplication would be the most plausible explanation for the observed findings. Thus, present patient would represent a further example of diplodization in humans.

The diagnosis of Beckwith-Wiedemann syndrome was established at birth in a girl of healthy and non-consanguineous parents because of macrosomia, overgrowth, hypoglycaemia and hemihypertrophy. The patient is included as part of a Research Program in the Spanish Overgrowth Syndrome Registry (IRB-HULP PI446). At birth she weighed $3750 \mathrm{~g}$, and showed capillary malformations in legs, hands and thorax, contracture of fingers, facial asymmetry and hemihypertrophy of left hand and leg. She continued with hypoglycaemia and needed treatment with diazoxide for years. At 16 months she had episodes of convulsions needing valproic acid treatment. She started to walk at 19 months. Language was delayed and her school performance was lower than average for age. At age 9 years she underwent pancreatic resection due to intractable, symptomatic hypoglycaemias. At age 4 years 5 months a grade II mesenchymal Wilms tumor was diagnosed and received a combination of complete nephrectomy (including right adrenalectomy) and 9 months of chemotherapy. She also had renal stones (calcium) needing close follow-up for her unique kidney. Calcium, phosphate, alkaline phosphatase, and PTH were among normal ranges. She has an average height for Spanish standards $(163.5 \mathrm{~cm}$; $50^{\text {th }}$ centile). Skeletal surveys were normal except for the slight asymmetry due to hemihyperplasia. Her clinical outcome was then unremarkable until 20 years when an ectopic adrenocortical virilizing adenoma was suspected (and confirmed) due to hirsutism, secondary amenorrhea and the finding at MRI of an abdominal retroperitoneal mass, independent from the left adrenal gland. An excision surgery was followed by complete recovery. Six years later she remains asymptomatic, with normal adrenal function and regular menses. The patient is now 26 years old and works as administrative assistant. 
Standard karyotyping along with single nucleotide polymorphism (SNP) and HumanMethylation 27 Infinium arrays, microsatellites, Methylation Specific-Multiplex Ligation dependent Probe Amplification (MS-MLPA), Methylation Sensitive-High Resolution Melting Assay (MS-HRMA), pyrosequencing, and array-CGH were performed on patient's samples (see Supplementary methods).

The diagnosis of BWS due to patUPD11p15 was suspected upon microsatellite analysis in the patient and her parents and confirmed through MS-MLPA (Fig. 1A,B). As expected, MSHRMA and pyrosequencing of specific CpG dinucleotides in the KvDMR and H19DMR, further delineated the degree of aberrant methylation reflecting the percentage of the patUPD11p15 (Fig. 1C-F).

SNP-arrays showed an abnormal, unforeseen, unusual pattern not only at chromosome 11 but also in all chromosomes. The Log $\mathrm{R}$ ratio (which evaluates the genomic dosage, e.g. deletions/duplications) was between normal ranges in all chromosomes but the allele frequency (evaluation of homozygosity/heterozygosity of each SNP) disclosed an almost complete drift ( $\sim 85 \% \mathrm{LOH})$ to homozygosity in all chromosomes (Fig. 2A and Supplementary Fig. 1). Subsequent microsatellite analyses of several chromosomes confirmed in blood, skin, urine, buccal cells and some tissues (Wilms tumor, adrenal, ceccal appendix) that almost all of the genomic contribution was paternal with a minimum, low mosaic maternal contribution (Supplementary table 1). All tissue showed a similar pattern with different degree of mosaicism. Calculation of the percentage of mosaicism was applied to some tissues and showed an average contribution of $\sim 85 \%$ from the paternal genome and $\sim 15 \%$ of maternal genome (Supplementary table 1). Analysis of microsatellites of $\mathrm{X}$ chromosome in the patient indicated that in most cells both X chromosomes came from the only paternal X chromosome with only a minimum fluorescence of maternal markers ( 15\%) (Supplementary Fig. 2). SRY and amelogenin amplifications were indicative of absence of $\mathrm{Y}$ chromosome in the patient (data not shown). 
Using MLPA targeting the Prader-Willi and Angelman syndrome (PW/AS) and Pseudohypoparathyroidism (PHP) loci, and the Illumina Infinium DNA-methylation BeadArray, we were able to clearly show the lack of appropriate allelic methylation in the patient at 14 DMRs located on 7 different autosomes. These included the maternally methylated SNPRN, NDN, GNAS XL, GNAS EX1A, GRB10, MEST, PEG10, PEG3, ZAC/PLAGL1, L3MBTL, $K v D M R / K C N Q 1$ and DIRAS3, as well as the paternally methylated NESP and H19 DMRs (Fig. 2B). These results confirm the methylation profiles determined by both the MS-MLPA and MSHRM assays.

There have been scant reports of genome-wide paternal UPD in the literature [14] and as far as we know our case is the only adult patient reported to date. Three patients with proved genome-wide paternal UPD developed pediatric tumors (pheochromocytoma, hepatoblastoma and pancreatic tumor) $[13 ; 15]$ and another two individuals without tumors have been recently reported $[11 ; 16]$. These cases presented with combined features consistent in part with known imprinting disorders associated with paternal UPD of specific chromosomes, but the most pronounced phenotypic features in all cases resembled patUPD11/BWS. Other authors have described genome-wide paternal UPD confined to specific tissues but not present in blood $[12 ; 17]$ or exclusively confined to placenta and not to fetal tissues [18-21]. Although, the percentage of uniparental cells has not been calculated in all reports the patient presented herein showed one of the highest mosaicism ( $\sim 85 \%$ in blood, $65-87 \%$ in other tissues).

In fitting with these previous reports, our patient showed clinical features of some classical paternal UPD syndromes (Supplementary Fig.4). She showed capillary malformation, hemihyperplasia, macroglosia, Wilms tumor and adrenocortical tumor (patUPD11), linear hypopigmentation, seizures and low-average mental development (patUPD15) and hypotonia (patUPD14). The observation of BWS phenotype in this woman is in agreement with our laboratory findings since patUPD11p15 is observed in about $15-20 \%$ of individuals with BWS. Furthermore, both tumors observed in the patient, Wilms tumor at 4 years and extra-adrenal 
adrenocortical tumor at age 20, are also prevalent in BWS. Somatic pat11pUPD15 has been encountered in about one third of Wilms tumors [22] and such a tumor is the commonest neoplasia observed in BWS patients encompassing about half of tumors reported in this disorder [2].

Regional or partial LOH is observed in deletions or UPDs. In the present patient, deletion was ruled-out due to normal $\log \mathrm{R}$ ratios in the CGH-array and SNP-array. In addition, almost complete LOH in all chromosomes observed by means of SNP-arrays, microsatellite analyses, MS-MLPA and MS-HRM is consistent with a mechanism of genome-wide UPD.

Potential mechanisms of genome-wide UPD are diploidization of an initial triploid foetus or a normal fertilization followed by a failure of replication and chromosome condensation of the maternal pronuclei with normal replication and segregation of the paternal chromosome (Supplementary Fig. 5). We discarded diploidization after dispermic triploidy as a possible mechanism because the microsatellite analysis in our patient revealed the involvement of a unique X-bearing sperm. We believe that the most probable and simplest explanation for our case is normal fertilization followed by failure of maternal DNA replication and paternal genome endoreduplication, resulting in androgenetic/biparental mosaicism, with over-representation of the genome-wide paternal UPD cell lines (Supplementary Fig. 5E). This diploidization, the recovery of the normal diploid human chromosome number $(2 n=46)$ is common in plants and is in some ways similar to "trisomy rescue" observed in UPD, when trisomic cells (47 chromosomes) recover to normality loosing the extra chromosome in the next division. The pathological consequences of UPD are identical for a single chromosome as a results of trisomy rescue or for the entire genome due diploidization.

Differences in gene expression between the allele inherited from the mother and that inherited from the father are the result of genomic imprinting, and it is the most frequent molecular aberration in BWS. Thus, BWS patients carrying a mosaic paternal UPD of chromosome 11p15 have increased risk of cancer, mainly Wilms tumor, hepatoblastoma and 
others embryonal tumors [2;23]. Further, the frequency of UPD detected in neoplastic tissues varies from 3 to $100 \%$ [8]. The patient reported herein developed two different neoplasias: Wilms tumor and adrenocortical neoplasia. Consistent with this observation, chromosome 11p15 UPD is observed in 30-40\% and 32\% of Wilms and adrenocortical tumors, respectively [22;24].

Aberrant allelic methylation at all loci analyzed was demonstrated in the patient by means of MS-MLPA, MS-HRMA, pyrosequencing and methylation array (Fig.1B-F and 2B). Analysis of the BWS, PW/AS and PHP regions revealed a methylation level partially abnormal due to the mosaic status; such an aberrant methylation led to abnormal imprinting of these loci. Thus, our patient showed typical clinical findings of BWS but not typical features of AS, PHP or transient neonatal diabetes mellitus (TNDM), demonstrating that partial loss of imprinting is sufficient for developing BWS but not sufficient for others disorders which usually requires total LOI to manifest the clinical features of the diseases. In addition, the lack of atypical BWS phenotypic features also suggests that inappropriate methylation at the MEST, L3MBTL, GRB10, PEG3, and DIRAS3, as revealed by the methylation array, is not associated with obvious dysmorphologies. However, the resultant increase in expression of the paternally expressed imprinted genes, due to biallelic expression, and the loss of maternally expressed transcripts maybe involved in tumorigenesis in this patient.

Because of the patient had two different cancers and she carried genome-wide paternal UPD, she may theoretically have increased risks for additional UPD-related tumors [8]. Thus, her prospective follow-up raised some important questions because there are no published recommendations for clinical evaluation schedule and survey for these individuals. Classic recommendations for cancer surveillance in general population may or may not apply for her, since the genetic background is quite different and any cancer surveillance schedule in this patient should involve the whole body. Finally we empirically opted to evaluate this woman with regular (twice a year) clinical evaluation together with annual body MRI (including breasts), 
colonoscopy and a routine laboratory work- up including WBC and serological markers for cancer.

The demonstration of genome-wide paternal UPD has important implications for medical genetics, counseling and clinical oncology. Genomic technologies such as array-CGH, highdensity methylation and SNP-arrays should be incorporated in diagnostic workflows of patients with suspected imprinting/UPD disorders presenting with dysmorphic features and/or cancer. Tumor surveillance in these patients is empiric since neither guidelines are available yet nor enough experience has been accumulated for guiding the follow-up. Finally, the mechanism of diploidization should be taken into account in patients with genetic disorders and cancer because diploidization of triploid or haploid fetuses is now a recognizable, emerging mechanism with potential risk of UPD and consequently, high risk of neoplasia. 


\section{References}

[1] Beckwith. Extreme cytomegaly of the adrenal fetal cortex, omphalocele, hyperplasia of kidneys and pancreas, and Leydig-cell hyperplasia: Another syndrome? Western Society for Pediatric Research 1963.

[2] Lapunzina P. Risk of tumorigenesis in overgrowth syndromes: a comprehensive review. Am J Med Genet C Semin Med Genet 2005; 137C(1):53-71.

[3] Wiedemann. Familal malformation complex with umbilical hernia and macroglossia: A "new syndrome"? J Genet Hum 1964; 13:223-232.

[4] Li M, Squire JA, Weksberg R. Molecular genetics of Beckwith-Wiedemann syndrome. Curr Opin Pediatr 1997; 9(6):623-629.

[5] Li M, Squire JA, Weksberg R. Molecular genetics of Wiedemann-Beckwith syndrome. Am J Med Genet 1998; 79(4):253-259.

[6] Weksberg R, Smith AC, Squire J, Sadowski P. Beckwith-Wiedemann syndrome demonstrates a role for epigenetic control of normal development. Hum Mol Genet 2003; 12 Spec No 1:R61-R68.

[7] Henry I, Bonaiti-Pellie C, Chehensse V, Beldjord C, Schwartz C, Utermann G, Junien C. Uniparental paternal disomy in a genetic cancer-predisposing syndrome. Nature 1991; 351(6328):665-667.

[8] Tuna M, Knuutila S, Mills GB. Uniparental disomy in cancer. Trends Mol Med 2009; 15(3):120-128.

[9] Cooper WN, Luharia A, Evans GA, Raza H, Haire AC, Grundy R, Bowdin SC, Riccio A, Sebastio G, Bliek J, Schofield PN, Reik W, Macdonald F, Maher ER. Molecular subtypes and phenotypic expression of Beckwith-Wiedemann syndrome. Eur J Hum Genet 2005; 13(9):1025-1032.

[10] Golubovsky MD. Postzygotic diploidization of triploids as a source of unusual cases of mosaicism, chimerism and twinning. Hum Reprod 2003; 18(2):236-242.

[11] Morales C, Soler A, Badenas C, Rodriguez-Revenga L, Nadal A, Martinez JM, Mademont-Soler I, Borrell A, Mila M, Sanchez A. Reproductive consequences of genome-wide paternal uniparental disomy mosaicism: description of two cases with different mechanisms of origin and pregnancy outcomes. Fertil Steril 2009; 92(1):393399.

[12] Reed RC, Beischel L, Schoof J, Johnson J, Raff ML, Kapur RP. Androgenetic/biparental mosaicism in an infant with hepatic mesenchymal hamartoma and placental mesenchymal dysplasia. Pediatr Dev Pathol 2008; 11(5):377-383. 
[13] Wilson M, Peters G, Bennetts B, McGillivray G, Wu ZH, Poon C, Algar E. The clinical phenotype of mosaicism for genome-wide paternal uniparental disomy: two new reports. Am J Med Genet A 2008; 146A(2):137-148.

[14] Kotzot D. Complex and segmental uniparental disomy updated. J Med Genet 2008; 45(9):545-556.

[15] Giurgea I, Sanlaville D, Fournet JC, Sempoux C, Bellanne-Chantelot C, Touati G, Hubert L, Groos MS, Brunelle F, Rahier J, Henquin JC, Dunne MJ, Jaubert F, Robert JJ, NihoulFekete C, Vekemans M, Junien C, de Lonlay P. Congenital hyperinsulinism and mosaic abnormalities of the ploidy. J Med Genet 2006; 43(3):248-254.

[16] Bryke. Evolution of a complex phenotype in a unique patient with a paternal uniparental disomy for every chromosome cell line and a normal biparental inheritance cell line.: 2004. Abstract ASHG.

[17] Hoban PR, Heighway J, White GR, Baker B, Gardner J, Birch JM, Morris-Jones P, Kelsey AM. Genome-wide loss of maternal alleles in a nephrogenic rest and Wilms' tumour from a BWS patient. Hum Genet 1995; 95(6):651-656.

[18] Kaiser-Rogers KA, McFadden DE, Livasy CA, Dansereau J, Jiang R, Knops JF, Lefebvre L, Rao KW, Robinson WP. Androgenetic/biparental mosaicism causes placental mesenchymal dysplasia. J Med Genet 2006; 43(2):187-192.

[19] Makrydimas G, Sebire NJ, Thornton SE, Zagorianakou N, Lolis D, Fisher RA. Complete hydatidiform mole and normal live birth: a novel case of confined placental mosaicism: case report. Hum Reprod 2002; 17(9):2459-2463.

[20] Robinson WP, Lauzon JL, Innes AM, Lim K, Arsovska S, McFadden DE. Origin and outcome of pregnancies affected by androgenetic/biparental chimerism. Hum Reprod 2007; 22(4):1114-1122.

[21] Surti U, Hill LM, Dunn J, Prosen T, Hoffner L. Twin pregnancy with a chimeric androgenetic and biparental placenta in one twin displaying placental mesenchymal dysplasia phenotype. Prenat Diagn 2005; 25(11):1048-1056.

[22] Scott RH, Douglas J, Baskcomb L, Huxter N, Barker K, Hanks S, Craft A, Gerrard M, Kohler JA, Levitt GA, Picton S, Pizer B, Ronghe MD, Williams D, Cook JA, Pujol P, Maher ER, Birch JM, Stiller CA, Pritchard-Jones K, Rahman N. Constitutional 11p15 abnormalities, including heritable imprinting center mutations, cause nonsyndromic Wilms tumor. Nat Genet 2008; 40(11):1329-1334.

[23] Calvanese V, Horrillo A, Hmadcha A, Suarez-Alvarez B, Fernandez AF, Lara E, Casado S, Menendez P, Bueno C, Garcia-Castro J, Rubio R, Lapunzina P, Alaminos M, Borghese L, Terstegge S, Harrison NJ, Moore HD, Brustle O, Lopez-Larrea C, Andrews PW, Soria B, Esteller M, Fraga MF. Cancer genes hypermethylated in human embryonic stem cells. PLoS One 2008; 3(9):e3294.

[24] Tissier F, Louvel A, Grabar S, Hagnere AM, Bertherat J, Vacher-Lavenu MC, Dousset B, Chapuis Y, Bertagna X, Gicquel C. Cyclin E correlates with malignancy and adverse prognosis in adrenocortical tumors. Eur J Endocrinol 2004; 150(6):809-817. 


\section{Figure 1. Microsatellites, MS-MLPA, MS-HRM and CpG pyrograms of patient's blood sample.}

a) Genotypes of one microsatellite marker (THO1; $11 \mathrm{p} 15$ region), in peripheral blood from the patient, her mother and her father (from top to bottom). Note that in the patient, the maternal allele (157bp) is barely represented. b) MS-MLPA quantitative analysis of the 11p15 imprinting region in the patient. Black bars represent methylation values of the patient and grey bars represent the mean methylation values of the controls. Note hypermethylation of the 5 probes of H19DMR (mean methylation in controls $50.26 \%$ vs $89.68 \%$ in patient) and hypomethylation of the 4 probes of $K v \mathrm{DMR}$ (mean methylation in controls $54.69 \%$ vs $11.43 \%$ in patient) in the patient, corresponding to patUPD11p15. c, d) Normalized melting curves of H19DMR and $K v \mathrm{DMR}$, respectively, with curves of controls (C), $0 \%$ and $100 \%$ methylated DNAs; e, f) CpG pyrogram of $H 19 \mathrm{DMR}$ and $K v \mathrm{DMR}$ respectively, with methylation percentages calculation for each of the three $\mathrm{CpG}$ dinucleotides analyzed. Both analyses further demonstrate hypermethylation of the H19DMR and hypomethylation of the KvDMR. 


\section{Figure 2. SNP-array of chromosome 11 and methylation profile using Illumina Bead}

arrays.

a) SNP-array. The Log R ratio was between normal ranges but the allele frequency showed an almost complete drift ( 85\%) to homozygosity (loss of heterozygosity: LOH). Upper panel:

Black arrow showing no abnormal dose observed, ruling-out deletion/duplication. Lower panel:

Blue arrows denote homozygous SNPs; red arrows: SNPs in mosaic state tending to homozygosity; green arrow: almost absence of heterozygosity in the sample. b) DNA

Methylation profile of several imprinted genes evaluated through Illumina metylation BeadArray in lymphocytes of controls ('lymphocyte') and the patient ('pUPD'). The bar at the right grades from hypomethylation (green; 0.10) to hypermethylation (red; 0.90). Note that the majority of genes in the patient are extremely hypomethylated (green) and H19DMR and NESP are extremely hypermethylated (red). These results are in agreements with MS-MLPA and MSHRM. 
"The Corresponding Author has the right to grant on behalf of all authors and does grant on behalf of all authors, an exclusive licence (or non exclusive for government employees) on a worldwide basis to the BMJ Publishing Group Ltd to permit this article (if accepted) to be published in Journal of Medical Genetics and any other BMJPGL products and sublicences such use and exploit all subsidiary rights, as set out in our licence (http://group.bmj.com/products/journals/instructions-for-authors/licence-forms)."

Competing Interests: None to declare 


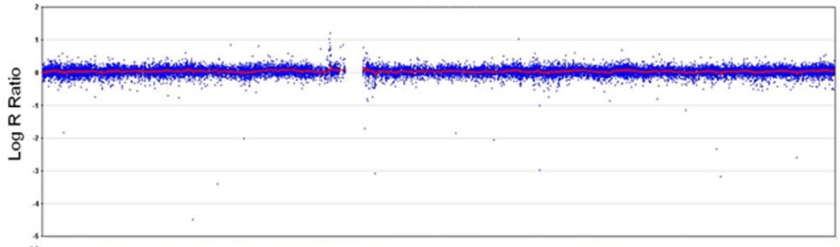

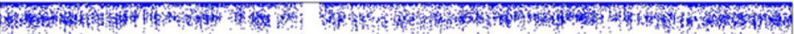
$\frac{\Phi}{\frac{\Phi}{4}}$

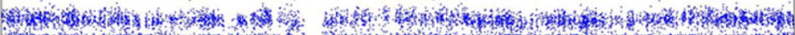

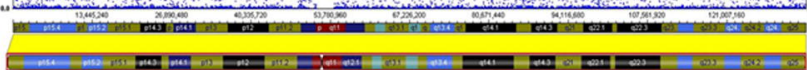

b

chr.

$\begin{array}{ll}1 & \text { DIRAS3 } \\ 6 & \text { PLAGL1 }\end{array}$

$7 \quad \begin{aligned} & \text { GRB10 } \\ & \text { PEG10 } \\ & \text { MEST }\end{aligned}$

$11\left\{\begin{array}{l}\text { H19 } \\ \text { KvDMR }\end{array}\right.$

$15\left\{\begin{array}{l}\text { NDN } \\ \text { SNURF }\end{array}\right.$

19 PEG3

$20\left(\begin{array}{l}\text { L3MTBL } \\ \text { NESP } \\ \text { GNAS XL } \\ \text { GNAS EX1A }\end{array}\right.$
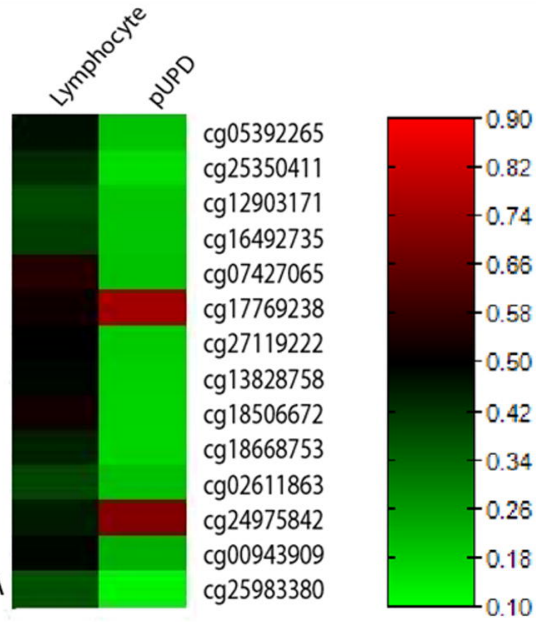